\title{
Work Ethics, Values, Attitudes and Performance in the Nigerian Public Service: Issues, Challenges and the Way Forward
}

\author{
Bernard Oladosu Omisore, Ph.D \\ Centre for Management Development, Shangisha, Lagos, Nigeria \\ E-mail: bernardoladosu@yahoo.com
}

\author{
Oyende Adeleke A. Ph.D \\ Department of Economics, College of Business and Social Sciences, \\ Crawford University, Faith City, Igbesa, Ogun State, Nigeria. \\ E-mail: lekeloo@yahoo.com
}

Accepted: March 19, 2015

Doi:10.5296/ jpag.v5i1.7367 URL: http://dx.doi.org/10.5296/ jpag.v5i1.7367

\begin{abstract}
Performance of the Nigerian public service has been a major concern to policy makers and researchers alike. This is because despite all measures put in place to arrest the ugly trend, it seems, it has defied all approaches towards tackling the problem of inefficiency and capacity collapse. Work ethics, attitudes and values can be influenced by the organization, through interventions like training, motivation and coaching, etc. However, they cannot be changed forcibly because they are intrinsic. It is, therefore, of fundamental importance that public functionaries act justly and fairly to all, not only paying lip service to ethical conduct but also ensuring that these are manifestly and undoubtedly seen to be done. This paper discusses the challenges of work ethics, values, attitudes and performance in the Nigerian public service. The major causes of unethical conduct in the public service were identified and the institutional mechanisms established by the government to curb these unethical behaviours were examined. This paper adopted content analysis as a method of data gathering and analysis. It suggested viable options for effective and efficient service-oriented public service.
\end{abstract}

Keywords: Work Ethics, Values, Attitudes, Performance, Public Service, Challenges, etc. 


\section{Introduction}

All over the world, changes are daily taking place. This change affects all countries and Nigeria is no exception. No wonder a philosopher once said that the only permanent thing in life is change, since all is always becoming. Nothing is static in life. Thus, the Nigerian work environment has become susceptible to change, considering the dynamic and complex issues that are faced daily. The emerging trend in work that is beginning to serve as a mark of distinction or critical edge is the level of work ethics and values that is domiciled within an organization.

In the face of the emerging world economy, an organization that is involved in a proper framework for good governance must practice work ethics and incorporate good values as part of its organizational culture if it must achieve higher performance.

Work ethics, attitudes and values affect the performance of every organization. This is because the human resource is the most important resource in every organization. The performance of every organization is tied to the performance of every member of staff. Values are the foundation upon which individual ethics and attitudes are built. These three components (attitude, ethics and values) shape an individual's character. A person's character is manifested in his/her words and actions (behaviour).

\section{Work Ethics Issues}

Work ethics can simply be referred to as a set of principles relating to morals, especially as they apply to human conduct. In specific terms, work ethics is about what is morally correct, honourable and acceptable to the larger majority of the people of an organization, society or group. It is also the rules of conduct that have become a set of norms of the society, group or organization.

Ethics deal with what is right and wrong as well as moral duty and obligation. Work ethics can be described as a set of values, which include the right attitude, correct behaviour, respect for others and effective communication in the workplace. Essentially, work ethics regulate what an employee would do in different situations in the organization. The habit of following good work ethics is intrinsic, i.e. it comes from within.

The work ethics an individual displays come from his/her values. Our values are dependent on our environment, experiences and life-long influences. These influences include our parents, teachers, friends, peers, competitors, etc, anyone or anything that has helped to shape or form our opinion of the world.

Workers exhibiting good work ethics are considered eligible for higher positions and more responsibilities. They know that their actions have a direct impact on other people at work. This conscientiousness persuades them to cultivate a responsible outlook to every action they take. These people do not need prodding or constant supervision. They are self-motivated and valuable to their organizations. These workers are highly reliable and are appreciated by their superiors for what they bring to the work place.

They are honest, responsible and dependable assets to their organizations. 
Managers have a responsibility of creating an organizational environment that encourages good work ethics and ethical decision making by institutionalizing ethics. This means applying and integrating ethical concepts into daily operations in their various organizations. Theodore Purcell and James (2011) suggested that this can be accomplished in three ways by:

i. establishing an appropriate organization policy or a code of ethics;

ii. using a formally appointed ethics committee; and

iii. teaching ethics in management development programmes.

The commonest way to institutionalize ethics is to establish a code of ethics. However, publishing a code of ethics is not enough. Some organizations require employees to sign the code and include ethics criteria in performance appraisal.

Also, some other organizations connect compensation and rewards to ethical rewards. Managers should also take any opportunity to encourage and publicly reward ethical behaviour. Employees should be encouraged to report unethical practices to management. Most importantly, managers must set good example through ethical behaviour and practices. All workers must act ethically and ignore widely accepted social standards that inflict harm on others.

A code is a statement of policies, principles or rules that guide behaviour. Codes of ethics do not apply only to government or business enterprises. They should guide the behaviour of persons in all organizations and in everyday life. The existence of an organization's code of ethics and any governance structure put in place to support that code of ethics should be disclosed to all members of staff. Any waivers to the code of ethics or the rules governing ethics procedures should be disclosed as well.

Details of the code of ethics must be widely circulated including:

$>$ the existence of an ethics committee and its responsibilities;

$>$ the sanctions for breaches of the code of ethics;

$>$ reporting mechanisms and "whistle blower" protection mechanisms; and

$>$ policies on the dissemination and promotion of the code of ethics.

\section{Influences Shaping Contemporary Work Ethics}

Work ethics is a cultural norm that places a positive moral value on doing a good job and is based on a belief that work has intrinsic value for its own sake (Carrington, 1980; Quinn, 1983; Yankelorich, \& Immerwahr, 1984). Like other cultural norms, a person's adherence to or belief in the work ethics is principally influenced by socialization experiences during childhood and adolescence (Akonti, 2013). Through interaction with family, peers, and significant adults, a person "learns to place a value on work behaviour as others approach him in situations demanding increasing responsibility for productivity" (Braude, 1975). Based on praise or blame and affection or anger, a child appraises his/her performance in household chores, or later in part-time jobs, but this appraisal is based on the perspective of others. As a 
child matures, these attitudes toward work become internalised and work performance is less dependent on the reactions of others (Akonti, 2013).

One other significant factor shaping the work attitudes of people is the socialization which occurs in the workplace. As a person enters the workplace, the perceptions and reactions of others tend to confirm or contradict the work attitudes shaped in childhood (Braude, 1975). The occupational culture, especially the influence of "an inner fraternity" of colleagues, has a significant impact on the attitudes toward work and the work ethic which form part of each person's belief system.

Among the mechanisms provided by society to transfer the culture to young people in the public schools. One of the functions of schools is to foster students understanding of cultural norms, and in some cases recognize the merits of accepting them. Vocational education, for example, has as a stated goal that it will promote the work ethics (Gregson, 1991. Miller, 1985). Also, Reubens (1974) listed "inculcation of good work attitudes" as one of the highest priorities for high school education. In the absence of early socialization which supports good work attitudes, schools should not be expected to completely transform a young person's work ethic orientation, but enlightening students about what the work ethic is, and why it is important to success in the contemporary workplace, should be a component of secondary education.

\section{Role of the Public Service of Nigeria}

The Nigerian public service is an embodiment of the civil service, line ministries and extra-ministerial agencies. It also includes states and national assemblies, the judiciary, the Armed forces, the police and other security agencies, the paramilitary services, parastatals and agencies.

The public service in Nigeria plays a lot of roles in the policy. These roles include giving professional and technical advice on government policies based on knowledge, experience gained over a long period of service and expertise.

It is also the role of the public service to develop programmes of project execution by government and the project options based on available resources.

The public service of Nigeria also ensures the implementation of all government policies and programmes for the achievement of set goals and objectives.

Another role of the Nigerian public service is the monitoring and evaluation of all on-going government projects and programmes to ensure they comply to plans and adequately or properly implemented.

Also, the Nigerian public service ensures operation of development consciousness, performance oriented, effective and efficient administrative system. The public service also provides for promoting the dynamic growth of socially responsible private sector within the framework of national economic objectives.

It acts as a springboard for public policy, especially where the political leadership is weak. It 
provides for continuity in governance and serves as a store house of knowledge of past government decisions and procedures.

\section{Code of Conduct in Public Service}

The Code of Conduct Bureau and Tribunal Act, the Civil Service Rules, and Financial Regulations have set ethical standards in the Nigerian public service. They include:

Discipline: Those officers who wish to lead other people should be disciplined people. They should always remember that effective leadership involves exemplary character, hard work and transparent integrity. Good conduct is one of the criteria for promotion. Officers should be familiar with government regulations and rules regarding good conduct.

Loyalty: Officers who want to lead must ensure they possess and display unquestionable loyalty to their superiors as well as the government of the day. They must put loyalty to the highest moral principles and to the country above loyalty to persons, party or government department.

Honesty: Civil servants should be honest in carrying out their duties and in their dealings with the public. They should realise that they are paid salaries for the duties which they perform; and demand or receive nothing in money or kind from anyone in the performance of their duties except their normal entitlements.

Courage: Civil servants must be courageous in carrying out their duties. They must never discriminate by the dispensing of special favours or privileges to anyone, whether for remuneration or not; and never accept, for himself or herself or for family members, favours or benefits under circumstances which might be construed by reasonable persons as influencing the performance of duties.

Courtesy: Civil servants must be polite at all times in executing their daily duties. It costs nothing to be polite to your colleagues and the general public served by you. Remember that polite instructions are usually more easily obeyed. Also, members of the public always cherish courtesy and consideration for civil servants. Courtesy in the office and to the general public makes it easier to get on with other people. In fact, a loaded schedule of duties or any other circumstance cannot justify bad temper by civil servants.

Co-Operation: As no one is an island, no one is totally independent. We all need each other for survival. Nobody knows it all. It is imperative for all staff in the department of a ministry to cooperate as a team in order to realise the overall objective of the department. The officers and staff of a ministry should work together as a team to attain the goals of the ministry.

Tact: "Tact" means skilfulness in handling a difficult situation without giving offence to the people involved. This is very necessary in the public service. Skill in dealing with people by creating an impression of willingness to be of assistance enhances the efficiency of the office and gives the public satisfaction. Uphold these principles, ever conscious that public office is a public trust. 


\section{The Concept of Values}

Values are important element of culture and other social and technical systems in an organization. Values are things held in high esteem by a society which it adheres to tenaciously. In any society, behaviour is guided by values.

Every organization or society has its own culture practice and values. Societal or corporate values provide the underlying force for individual and group action. Corporate values, beliefs and guidelines dictate how an organization conducts its business. Corporate values can be found in the mission statements of organizations. Corporate values are those things which make organizations thick.

\section{Key Issues in Values}

In developing organizations value systems, consideration should be given to the identification of the core values and other peripheral values. The core values are the main driving force of the organization while the peripheral values are derivatives of the core or main values.

In developing organization's values, effort should be made to ensure that all segments of the organization are involved in its development. This means that from the drafting to the review and finally to the adoption of the core values. This will make the final communication to be easy since all sections were involved in its development. It would also be easy for all stakeholders to share these values as they too, were involved in its development. Thus understanding the values would not pose any problem as all sectional heads would ensure it simmers down through education and enlightenment.

\section{Values in Organizations}

All organizations exist with clear goals and objectives of their being set up. These goals of the proprietors or shareholders of such organizations are the reasons for the organization's existence. These should be clear enough for all stakeholders.

For these goals to come into manifestation, there must be commitment to strategic planning. Without strategic planning, achievement of the organization's goals and objectives may become a mirage. Again, these goals must be customer centred. Otherwise, the organization may be forced to close shop sooner than later.

Another value of an organization is quality staffing and staff welfare with good motivational system for staff as well as customers. Staff that are not well qualified, and with low skills will only be a liability to the organization. Organisations can only meet the yearnings and aspirations of stakeholders if well trained and adequately equipped staff are employed to man the various arms of operation.

Again, organizations exist to make profitable operations. Without profit, organizations would find it difficult to continue in operation. Organizations can continue to be in profitable operations if they are cost conscious. Cost consciousness should always be taken very seriously as that can be the determinant of whether or not the organization can continue to be in existence or close shop. 
Again, transparency and accountability are other values of any organization. An organization that is not transparent and accountable is on the threshold of collapse. This is because a transparent and accountable organization does not give room for rumours. There will be no strikes or work-to-rule in such organizations since the workers are in the know of the goings on in the organizations.

Innovation and technology is another value of organizations. This is more so as we live in a dynamic society where dynamism is the key thing. Things are frequently changing and any organization that refuses to change along the direction of society world sooner than later go into extinction. Thus, organizations must be prepared to embrace change in technology to be in competition with others.

Strong financial base is also one of the values of any organization. Organizations need strong financial base to be able to embrace new innovation and technology. Every new change costs money. Hence organizations that want to embark on new technology or innovation require finance.

\section{Developing Shared Values}

Developing shared values by organizations is not an easy thing to do. For organizations to develop shared values, they need committed leadership. Committed leadership is the driving force for the development of shared values. Without leadership commitment, organizations would be embarking on futile exercise.

Any leader who wants to succeed in the development of shared values must use participatory style not dictatorial style. With participatory or democratic style, all are involved and carried along. They all take the outcome as theirs and not the leaders'. They work together to ensure its success as they would share the failure or success together as a team.

Leaders should also ensure that effective communication is put in place for successful implementation. This would prevent any rumour from being circulated. It would also eliminate I-don't-care attitude of some staff who would distance themselves since according to them, they were not taken along in the first place.

For the development of the shared values to have any effect, there should be staff orientation or re-orientation on the organization's values system. There should also be staff training and development to equip staff with organization's value.

There should put be in place conducive organizational climate. With good working environment, the imbibing of the organization's value culture would be easy but without conducive organizational climate the shared core values of the organization may make little or no meaning at all.

For the development of organizational shared value to succeed, there must exist effective reward systems. It is not nice only to blame when a job is poorly done. It is also necessary to praise as applicable. Humans love being praised. Reward is an impetus for workers to do more. Thus, effective reward system can be the springboard the organization needs for effective development of shared values. 


\section{Changing Attitude for Improved Performance}

Attitude is an internal state of person that is focused on objects, events, people that can exist in the person's psychological world. It remains inside the person (Ekenimoh, 2013). The attitudes of employees in the work place can have a significant effect on the business as a whole. Attitude is one of hidden, hard-to-measure factors that end up being crucial to the success of an organization. Whether for better or for worse, employee attitudes tend to have a drastic impact on the productivity of an organization, both directly and through the effect on other job-related factors.

In sales or service-based industry, negative attitudes are very toxic and could destroy an organization. Customers are an annoyance and an inconvenience to employees with bad attitude. On the other hand, a positive and engaged attitude is likely to result in courtesy, emotional engagement and a real concern for the well-being and satisfaction of the customer.

According to Brian Tracy (2003), the average employee works at only 50\% of capacity. Employee attitude is a major reason for this anomaly. There are many factors affecting employee attitude. These include:

$>$ Values;

$>$ Work conditions including supervisors, tools, company policies, company cultures, etc;

$>$ Competence; and

$>$ Commitment

In business organizations, employees have attitudes related to the world environment, job security or uncertainty, prestige of the product or department and plant location, etc. The individual's attitudes towards these factors are indicative of his/her apathy or enthusiasm towards the activities and objectives of the organization. The notable feature of attitude is that it varies in:

$>$ Direction (favourable - unfavourable);

$>$ Intensity (how strongly it is held); and

$>$ The extent of consciousness (awareness of individual concerning his/her attitudes).

Managers in organizations need to know and understand employees' attitudes in order to manage effectively. Attitudes play a critical path in the job selection, promotion and development process.

\section{Properties of Attitude}

(a) Attitude once formed is relatively permanent;

(b) Attitude can be either negative or positive;

(c) Attitude permits people to construct an orderly framework of recognition and 


\section{Macrothink}

Journal of Public Administration and Governance

behaviour based on the life-standards determined by their central values;

(d) Attitude is valence-magnitude or degree of favourableness or unfavourableness towards an object/event;

(e) Multiplicity of attitude refers to the number of elements constituting the attitude; and

(f) Attitude is related to the needs it serves (Ekenimoh, 2013).

\section{Functions Served By Attitudes}

Attitudes serve four important functions and these are:

1. Adjustment Function: Attitudes are the means for reaching desired goals or for avoiding undesirable results.

2. The Ego-Defensive Function: This is the function of defending our self-image. For instance, when people cannot admit their inferiority feelings they protect their feelings over some convenient minority group and bolster their egos by attitudes of superiority towards this minority group.

3. The Value-Expressive Function: This function in terms of positive expressions of an individual in the minds of other people. These attitudes give clarity to the self-image but also mould that self-image closer to the heart's desire.

4. The Knowledge Function: This function is based on the need for understanding and making sense of the world. Attitudes that are appropriate to situations will be retained and outdated ones will be discarded by an employee because they lead to contradictions and inconsistency (Ekenimoh, 2013).

\section{Work Attitudes and Performance}

In organizations, attitudes are important because they affect job behaviour. A person has thousands of attitudes but focus shall be on job attitudes in this paper. These are:

(a) Job Satisfaction: This refers to an individual's general attitude towards his/her job. A person with a high level of job satisfaction holds a positive attitude whereas the person with low level of job satisfaction holds a negative attitude about the job.

(b) Job Involvement: This attitude measures the degree to which a person identifies with his/her performance important to his/her self-worth. Individuals that express high involvement in their jobs are likely to be more productive, have higher satisfaction and are less likely to resign than employees with low involvement (Ekenimoh, 2013).

(c) Organizational Commitment: This attitude expresses an individual's orientation towards the organization by which he/she identifies with a particular organization and its goals and wishes to maintain membership in the organization (Ekenimoh, 2013).

\section{Changing Attitudes}

People strive to maintain "Cognitive consistence", that is a psychological balance between 
the three attitudinal elements: beliefs, feelings and actions, and between different attitudes.

Attitude change can be classified into two, viz:

- Congruent Change: This is a movement in the same direction, e.g. a less serious student may become more serious by attitude change.

- Incongruent Change: change towards the other end of the continuum e.g. conversion of a dull and non-intelligent student into an intelligent student constituents this attitude change (Ekenimoh, 2013).

Other attitude change are turning dislike into like, unfavourable into favourable.

\section{Enhancing Employee Performance/Productivity}

Enhancing employee performance/productivity is hinged on four of the most common motivating factors, viz:

(a) Challenging, interesting work;

(b) An environment of Mutual Trust and Open Communication;

(c) Management Support (provide tools, training, etc.); and

(d) Opportunities for personal growth and promotion

Employers of labour expect personnel to behave in a manner consistent with the organization's mission and goals. By establishing standards for business conduct, management set expectations about acceptable behaviour. Positive attitudes usually create a productive environment in which people take pride in the work, and customers, suppliers and partners want to conduct business.

\section{Respect and Communication}

By demanding that all employees value each other's opinions and treat all stakeholders with dignity, companies ensure that employees show respect in the workplace. If employees have negative attitudes toward other employees because they come from a different culture or religion, productivity tends to decrease. By promoting activities that help teams work together better, such as workshops with team-building exercises designed to improve communication, solve problems and make decisions effectively, organizations help their employees improve performance/productivity.

\section{Cooperation and Teamwork}

Effective managers foster cooperation and collaboration by involving subordinates in the decision-making process. By developing skills in conflict management, these managers help minimize disruptions in productivity causes by needless conflict. Leading by example, effective managers maintain a high level of integrity and communicate honestly and openly to their subordinates. Team members who trust their superiors and feel valued tend to have higher job satisfaction and a positive attitude toward their job. This typically leads to higher productivity, reduced operational costs and improved customer satisfaction. 


\section{Appearance and Character}

Employees who demonstrate a positive attitude toward their job typically respect organization rules and follow the organization's dress code, obey safety procedures, adhere to ethical standards and exercise self-discipline at all times. Organization policies regarding work ethics typically require employees to consider how their behaviour would look if reported in the news. If an employee would be uncomfortable being judged poorly by the public for his/her actions, he/she should not take an action that would condemn him/her. Immoral and unethical behaviour causes distractions that reduce performance and disrupt the work environment for everyone.

\section{Attendance and Organization}

By arriving on time and leaving at the scheduled time, effective employees usually produce the work they were hired to complete. Repeated unexplained absences or missed appointments reduced productivity, which tends to affect the rest of the organization. By displaying a positive attitude toward work, employees get work done in timely manner and ensure customer satisfaction. Organizations that deal with misconduct in a consistent manner and prevent retaliation against employees who report bad behaviour ensure high ethical standards that lead to employee trust, respect and productivity/performance.

\section{Performance}

According to Dare Arowolo (2012), performance is an action that involves a lot of efforts aimed at achieving a purpose. Performance is measured on a given set of standard to determine how well or badly a duty or an activity is carried out. Therefore, performance could be good or bad. For the purpose of this paper, performance can be defined in relation to the activities of a public servant most especially in terms of his/her efficiency in producing certain quantity of goods and services which his/her department produces in a day, week, month or year (Fatile, 2013).

\section{The Public Service}

The public service is a body or department in the executive arm of government with the responsibility of assisting in the planning and implementation of government policies. It is not profit-oriented but an institution established to deliver essential services to the people. Public service comprises of ministries, parastatals, agencies, corporations, etc. (Arowolo, 2012).

\section{Factors That Can Enhance Public Service Performance}

(a) Provision of Work Facilities: Employee should be provided with all necessary facilities he/she needs to work with. This will go a long way in enhancing employee's performance.

(b) Favourable Work Environment: Performance can only be enhanced where there is conducive atmosphere for his/her productivity. The friendly environment naturally elicits performance as there is cooperation rather than conflict; harmonious 
relationship in place of rancour.

(c) Capacity Building: Capacity Building is a mechanism put in place by organizations to increase the way an employee could work. In other words, capacity building involves training, creating opportunities for employees, and other means through which employees could perform better.

(d) Informal Group/Team Building: There is need to create informality out of formality. This, in a way, is capable of creating interactions which may not have been possible in an official relationship. This is also referred to as team building. Where all the employees and the employers; subordinates and the boss have time to relate, to discuss out of work environment and to share their grievances and what they think should be done to help enhance their performance.

(e) Performance Appraisal: Awareness of appraisal is capable of making an employee increase his/her performance, having known that there is time to evaluate his/her efforts and to reward or punish, depending on the efforts he/she puts into the production process (Arowolo, 2012).

\section{Challenges of the Public Service Performance}

Despite attempts by successive governments in Nigeria to ensure ethical standard, value and improve attitudes for better performance of the Nigerian Public Service, several challenges still militate against its being ranked as one of the best in the world. Some of these challenges include the following:

(i) The Nigerian public service tends to be portrayed as being rather self-seeking, venal and nepotistic (Takaya, 1989).

(ii) Unethical attitude and (non-accountability are other major challenges confronting the Nigerian public service (Beetseh and Kohol, 2013).

(iii) Fraud, extortion, embezzlement, bribery, influence peddling, bestowing of favours to friends also pose some challenges (Ayanda, 2012).

(iv) Corruption in the form of solicitation or acceptance, directly or indirectly by public officials or any other persons, of any goods of monetary, or other benefits, such as a (induced) gift, favour, promise or advantage for himself or herself or for another person or entity, in exchange for any act or omission in the performance, of his/her public functions. This include the offering or granting, directly or indirectly to a public official or any other person for the purpose of illicitly obtaining benefits for himself or for a third party; to mention just a few.

(v) Gross indiscipline is another challenge facing the public service in Nigeria. Today, gross indiscipline has manifested itself in different forms. The lack of accountability, unethical behaviour and corrupt practices have become so pervasive and even institutionalised norms of behaviour in Nigeria to the extent that one may conveniently speak of a crisis of ethics in the Nigerian public service 
(Rasheed, 1995).

All the above mentioned unethical behaviour and practices appear to have been institutionalised in Nigeria today for the fact that they seem acceptable and normal to the majority. Leaders do not frown seriously at such unethical practices and its negative impact on performance in the public service because in most cases they stand to benefit from it. Osaghae (1993) attributed all these challenges to colonial heritage. He argued that colonial heritage is a major factor responsible for ethical decay in the public sector. In the colonial days, the people were fond of stealing government money and property as a way of venting their anger and displeasures with the colonialists - an act often regarded as patriotic and heroic by the citizenry.

\section{The Way Forward/Recommendations}

A very dismal picture of the Nigerian Public Service has been portrayed but things have not gone beyond the point of no return. Things can be set right. Rasheed (1995) opined that repeated attempts have been made over the years to combat corrupt practices and unethical violations in Nigeria and other developing countries to curb the unethical behaviour in the public sector.

Thus, measures should be put in place to prevent undue interference in appointment, postings and promotions in the public service of Nigeria.

The autonomy of the civil service should be provided as it is the practice in the developed countries like the United Kingdom (U.K). Like the army, the civil service should be encouraged to remain a political and not get committed to a party or leader (Birkinshaw, 1993).

Moreover, effort should be geared towards installing political leadership in power which has both integrity and competence and which can be looked up to by the people with regard and respect instead of disdain as at present.

It is a matter of grave concern that in the field of education in Nigeria, ethics has become a casualty. Our temples of learning have become hotbeds of politics and violence. Therefore, the government must pay greater attention to education. Efforts should be geared toward having $100 \%$ literacy and the sanctity of the higher institutions of learning so mercilessly polluted by politics, corruption and criminalization should be restored.

In addition to the constitutional provision, Oladunni (2001) suggested that every public sector organization must have a code of conduct. All employees should be made to sign an undertaking that they will comply with this code of conduct. Organizations should additionally ensure firm and consistent application of appropriate sanctions when people violate the code of conduct (Fatile, 2013).

Government should also embark on moral campaign. This method helps in inaugurating massive propaganda and campaign calling for disciplined behaviour and practices of moral values among public servants. It is a moral evangelism of what is currently in place. This deadly disease of moral decadence should be addressed in public, private and governmental 
organizations.

Government should also institute a reward system of outstanding ethical behaviour. In a situation or instances whereby an individual displays an outstanding act of discipline behaviour, such behaviour should be rewarded in status, cash and kind (Adebayo, 2014).

Surely, all the above measures and more are necessary if we are committed to restoring the integrity of the public service in Nigeria and consequently increase its level of performance.

\section{Conclusion}

Work ethics, values and attitude can be influenced by the organization through interventions like training, motivation, coaching, etc. However, they cannot be changed forcibly because they are intrinsic in nature.

If these interventions fail to bring about improvement, stricter measures may be employed. The management of the organization has very important role in building the commitment of employees. The majority of people would like to work in an organization that:

- pays competitive wages in its industry of operation;

- provides opportunities for career advancement;

- provides equal opportunities for all; and

- deals fairly with all employees.

Upon gaining employment in such an organization, most people would like to work in such a place till their retirement. The challenge for the organization is to build such an institution and stay profitable at the same time.

Transparency and accountability are two important components of work ethics which are vital for effective service delivery and increased productivity. Success in creating a new work ethics will require a holistic action, whereas strict adherence to the work ethics and values of the public service will promote both the sector and invariably the Nigerian polity (Okeniyi, 2013).

Thus, the onus is on every employee to avail himself/herself of the Public Service Rules to guide his/her proper conduct and to enable him/her to enjoy the full benefits of the rights and privileges provided.

\section{REFERENCES}

Adebayo, A. O. (2014). "Ethical Issues in Public Service." International Journal of Social Science and Humanity, Vol. 4 No.5, September.

Agara, T. C. Olarinmoye, O. (2009). "Ethics and Accountability in Nigeria's Public Service: An Historical Overview.” Journal of Public Administration and Policy Research 1 (1).

Agishi (2007) Unpublished Lecture Notes on "Public Administration in Nigeria", Department of Political Science, Benue State University, Makurdi, Nigeria. 


\section{Macrothink}

Journal of Public Administration and Governance

ISSN 2161-7104

2015, Vol. 5, No. 1

Ake, C. (1981) A Political Economy of Africa, Ibadan, Nigeria, Longman.

Akhakpe, I (2001) "Bureaucratic Corruption in Nigeria." In Olojede I.A. and Fajonyomi, S. O. (Eds.) Ethics and Public Accountability in Nigeria. Lagos: A Triad Associates Educational Publishers and Printers.

Akinyemi, A. O. (2002) "Effective Business Training and Practice: The Ethical Side". In Adeseye, et al, (Eds.) Polytechnic Education in Nigeria: Problems and Prospects. Lagos, Bolufemi Enterprises.

Akonti, E. O. (2013). “Concept of Work and Ethics.” C.M.D Training Manual.

Ananda-Das, G. (1995). "Economic Management and Ethics: The Vedantic Answer." Indian Journal of Public Administration. XLI (3), July - September.

Anger, B. (2002) "Ethical Problems in Nigeria's Democratic Experiment: A Critical Analysis." African Journal of Economy and Society Vol.4, Nos.1 \& 2.

Asobie, A. (2001). "Ethics and University Administration" in Oloyede, I. A. \& Fajonyomi, S. O. (eds.) Ethics and Public Accountability in Nigeria. Lagos: A - Triad Associates Educational Publishers and Printers.

Asok, M. (1995). "Ethics in Governance: The Indian Perspective" Indian Journal of Public Administration. XLI (3), July - September.

Ayanda, D. O. (2012). "Corruption Definition, Theories and Concepts". Arabian Journal of Business and Management Review (OMAN Chapter 2(4)

Barrows, D. (2003). "Trends in Public Administration in Contemporary Administrative Systems". Vancouver, BC: The Commonwealth Learning.

Beetseh, K. and Kohol, B. (2013). Challenges of Ethics and Accountability in Nigeria Civil Service. Implication for Counselling (SR Journal of Humanities and Social Science Vol. 9, No. 2 .

Birknishaw P. (1993). "Ethics in Public Life in U.K". The Indian Journal of Public Administration. XLI (3), July - September.

Boss, J. A. (1998). Ethics for Life: An Interdisciplinary and Multicultural Introduction. Califonia: May Field Publishing Company.

Drucker, P. (1977). People and Performance: The Best of Peter Drucker on Management. New York: Harper and Row Publishers

Fleishman, J. L. and Payne, B. L. (eds.) (1980). Ethical Dilemmas and the Education of Policymakers. Hastings-on-Hudson, N.Y.: The Hastings Center.

Ibietan, J. and Joshua, S. (2012). Ethics in the Nigerian Public Sector: A Discourse. The Public Administration and Social Policies Review Vol. 1, No. 10. 


\section{Macrothink}

Journal of Public Administration and Governance ISSN 2161-7104

Ikotun, A. (2004). Ethics in the Nigerian Public Service: An Analytical Perspective. Lagos: Nuga Litho Productions.

Okeniyi, M. A. (2013). Work Ethics and Value: Unpublished Training Manual Centre for Management Development (C.M.D). Lagos, Nigeria.

\section{WEBSITE}

Fatile, J. O. (2013). "Ethics and Performance in the Nigerian Public Sector". Retrieved from www.garph.co.uk Vol.2/No.10/October IJARMSS/132.

Abiyeyi, S. (2014). Work Values and Attitude to Work in the Nigerian Public Service. International Journal of Research in Organizations Behaviour and Human Resource Management. Retrieved from www.aijsh.org.

Ocheni, S., et al (2013). Improving Staff Utilization and Productivity in the Nigerian Public Service through Training" Retrieved from: http:www.rcmss.com.

Arowolo, D. (2012). "Ethics, Motivation and Performance in Nigeria's Public Service". Journal of Public Policy and Administration Research. Retrieved from: http.www.iiste.org. 